\title{
El ius imperium de los tribunales ambientales en Chile**
}

\section{The ius imperium of the environmental courts in Chile}

RESUMEN

El trabajo analiza la manera como los tribunales ambientales ejercen su facultad de imperio para hacer cumplir las resoluciones por ellos proferidas, tanto en Chile como en el derecho comparado. Analiza la Ley 20.600 en lo pertinente, y la normativa de la fuerza pública y las fuerzas de orden del Estado. Finaliza acreditando la existencia efectiva de esta facultad de imperio, y plantea la necesidad de adecuar la normativa a la realidad actual del ordenamiento jurídico ambiental chileno.

PALABRAS CLAVE

Facultad de imperio, tribunales ambientales, Ley 20.600, cumplimiento, relación institucional.

\section{ABSTRACT}

The paper analyzes how the Environmental Courts exercise their power of empire to enforce their resolutions, shows how it has been exercised in Chile, and how it has been exercised in comparative law. It analyzes the 20,600 law in what is pertinent, and the regulations of the public force and forces of order of the State. It ends by proving the effective existence of this power

Abogado, magíster en Derecho Ambiental por la Universidad de Chile. Ministro del Ilustre Tercer Tribunal Ambiental de Chile. Profesor de posgrado de la Facultad de Ciencias Jurídicas de la Universidad Católica del Norte (Chile). Contacto: jorge.retamal@3ta.cl ORCID ID: 0000-0001-9244-8694.

** Recibido el 13 de junio de 2018, aprobado el 11 de junio de 2019.

Para citar el artículo: Retamal Valenzuela, J. R. El ius imperium de los tribunales ambientales en Chile. En Revista Derecho del Estado, Universidad Externado de Colombia. N. ${ }^{\circ} 44$, septiembre-diciembre 2019, pp. 257-284. DOI: https://doi.org/10.18601/01229893.n44.10 
of empire, and raises the need to adapt the regulations to the current reality of the Chilean environmental legal system.

KEYWORDS

Ius imperium, Environmental Courts, Law 20.600, Enforcement, Institutional Relationship.

SUMARIO

Presentación. 1. El concepto de ius imperium o facultad de imperio. 2. El ejercicio del ius imperium por parte de diversos tribunales chilenos que no pertenecen directamente al poder judicial y en el derecho comparado. 2.1. Tribunal de Propiedad Industrial. 2.2. Tribunales tributarios aduaneros. 2.3. Tribunal de Contratación Pública. 2.4. Tribunal de Defensa de la Libre Competencia. 2.5. Derecho comparado. 3. Fuente del ius imperium de los tribunales ambientales chilenos. 3.1. Antecedentes en la historia de la Ley 20.600.3.2. Fuente del ius imperium en la Ley 20.600.3.3. Reenvío y supletoriedad de las normas del Código de Procedimiento Civil. 4. Razonabilidad y proporcionalidad en el ejercicio de estas facultades. 5. Ejercicio del ius imperium por parte de los tribunales ambientales chilenos respecto de diversas instituciones del Estado. 5.1. Ejercicio del ius imperium respecto de Carabineros de Chile. 5.2. Ejercicio del ius imperium respecto de la Policía de Investigaciones de Chile. 5.2.1. Prohibición de actuar de la PDI respecto de los tribunales civiles. 5.3 Ejercicio del ius imperium respecto de Gendarmería de Chile. Conclusiones. Referencias.

\section{PRESENTACIÓN}

Los tribunales ordinarios tienen ius imperium -poder para usar los medios legítimos necesarios- para hacer cumplir sus resoluciones, conforme al Código Orgánico de Tribunales y demás normas pertinentes. En cuanto a los tribunales especiales, leyes específicas les han conferido esta facultad -así en el caso de los juzgados de familia o del trabajo-, pudiendo ordenar incluso el arresto para hacer cumplir sus resoluciones.

Los tribunales ambientales chilenos, agrupados por algunos autores como "tribunales administrativos especiales" ("aquellos tribunales especiales competentes para conocer de las reclamaciones o impugnaciones a la legalidad de un acto de la Administración del Estado en ámbitos específicos, los que han sido creados por el legislador en cada caso"1), son tres, con jurisdicción

1 FerRada, J. C. Los tribunales que ejercen la justicia administrativa en el derecho chileno. En Arancibia Mattar et al. (coords.). Litigación pública. Santiago: Thomson Reuters, 
acotada a las zonas norte, centro y $\operatorname{sur}^{2}$. Son permanentes, funcionan en sala -integrada por tres ministros titulares: dos abogados y un licenciado en ciencias- y sus acuerdos se adoptan por mayoría ${ }^{3}$. A los titulares se suman dos ministros suplentes: un abogado y un licenciado en ciencias, que integrarán la sala ante la inhabilidad o incapacidad de alguno de aquellos ${ }^{4}$.

Los tribunales ambientales no forman parte de la estructura orgánica del poder judicial, no obstante estar sujetos a la superintendencia directiva, correccional y económica de la Corte Suprema ${ }^{5}$; además, junto con el Ministerio del Medio Ambiente ${ }^{6}$, el Servicio de Evaluación Ambiental ${ }^{7}$ y la Superintendencia del Medio Ambiente ${ }^{8}$, conforman la institucionalidad ambiental de Chile ${ }^{9}$, completada con el Primer Tribunal Ambiental el 3 de julio de $2017^{[10]}$. Creados

2011, 119-150, cit. por Costa Cordella, E. Special Administrative Courts in Chile. [En línea]. En Revista de Derecho, Valdivia. Año 2014, vol. 27, n. ${ }^{\circ}$ 1, 151-167. Disponible en: https://scielo. conicyt.cl/scielo.php?script=sci_arttext\&pid=S0718-09502014000100007\&lng=es\&nrm=iso [Consultado el 18 de diciembre de 2018].

2 Ley.$^{\circ} 20.600$, que crea los Tribunales Ambientales, art. 5..

3 Ley n. ${ }^{\circ} 20.600$, que crea los Tribunales Ambientales, art. $6 .^{\circ}$.

4 Ley n. ${ }^{\circ} 20.600$, que crea los Tribunales Ambientales, art. 2. .

5 Ley n. ${ }^{\circ} 20.600$, que crea los Tribunales Ambientales, art. $10^{\circ}$.

6 Conforme a lo que señala la Ley 19.300 en su artículo 69, es la "Secretaría de Estado encargada de colaborar con el Presidente de la República en el diseño y aplicación de políticas, planes y programas en materia ambiental, así como en la protección y conservación de la diversidad biológica y de los recursos naturales renovables e hídricos, promoviendo el desarrollo sustentable, la integridad de la política ambiental y su regulación normativa".

7 Según los artículos 80 y siguientes de la Ley 19.300, es un "servicio público funcionalmente descentralizado, con personalidad jurídica y patrimonio propio, y sometido a la supervigilancia del Presidente de la República a través del Ministerio del Medio Ambiente" (art. 80). Y como función principal, entre otras, administra el Sistema de Evaluación de Impacto Ambiental ("ventanilla única" que establece la ley señalada, por la que se otorgan "los permisos o pronunciamientos de carácter ambiental, que de acuerdo con la legislación vigente deban o puedan emitir los organismos del Estado" (art. 8..$^{\circ}$.

8 La Superintendencia de Medio Ambiente es "un servicio público funcionalmente descentralizado, dotado de personalidad jurídica y patrimonio propio, sometido a la supervigilancia del Presidente de la República a través del Ministerio del Medio Ambiente" (Ley Orgánica de la Superintendencia del Medio Ambiente, art. $1 .^{\circ}$ del art. $2 .^{\circ}$ de la Ley 20.417). Tiene por objeto "ejecutar, organizar y coordinar el seguimiento y fiscalización de las Resoluciones de Calificación Ambiental, de las medidas de los Planes de Prevención y/o de Descontaminación Ambiental, del contenido de las Normas de Calidad Ambiental y Normas de Emisión, y de los Planes de Manejo, cuando corresponda, y de todos aquellos otros instrumentos de carácter ambiental que establezca la ley" (Ley Orgánica de la Superintendencia del Medio Ambiente, art. 2. del art. $2 .^{\circ}$ de la Ley 20.417).

9 Lo que puede colegirse del articulado de la Ley 20.417, de 28 de junio de 2012, que modificó la Ley 19.300, de 26 de enero de 2010, Ley de Bases Generales del Medio Ambiente.

10 Conforme al artículo primero transitorio de la Ley 20.600, el Segundo Tribunal Ambiental debía entrar en funcionamiento dentro del plazo de seis meses a contar de la publicación de la ley, lo que ocurrió el 28 de diciembre de 2012. No obstante, por razones diversas, y los dos restantes en los 6 meses siguientes, conforme al artículo segundo transitorio de la misma ley. Sin embargo, y por razones que escapan a la finalidad de presente estudio, el Tercer Tribunal Ambiental entró en funcionamiento el 7 de diciembre de 2013, y el Primer Tribunal Ambiental 
como control de la acción fiscalizadora de la Superintendencia del Medio Ambiente ${ }^{11-12}$, revisan y eventualmente invalidan los actos administrativos de carácter ambiental; conocen de las reclamaciones interpuestas en contra de resoluciones de la Superintendencia del Medio Ambiente, el Servicio de Evaluación Ambiental y otras entidades de la institucionalidad ambiental, conocen las demandas por daño ambiental y autorizan la aplicación de las máximas sanciones por la superintendencia antes mencionada ${ }^{13-14}$.

Su ley constitutiva, $n .^{\circ} 20.600$, de 28 de junio de 2012, no regula el ius imperium, reenviando para ello al Código de Procedimiento Civil, lo que genera dificultades interpretativas y prácticas al momento de su ejercicio, que pueden afectar la razonabilidad, proporcionalidad o la efectividad de sus decisiones, puesto que su ejercicio requiere el concurso de los organismos estatales para su cumplida ejecución; ya sea para levantar evidencias de daño, asegurar el cumplimiento de una medida cautelar o hacer cumplir una sentencia.

Este trabajo analiza el silencio del legislador, y la forma en que debió interpretarse para determinar las facultades conferidas a los organismos estatales con fines de apoyo al tribunal ambiental. Finalmente, considera la interpretación extensiva de los principios del derecho ambiental para justificar la necesidad de modificar las leyes pertinentes.

Luego de exponer el marco teórico, revisa el ius imperium de otros tribunales administrativos especiales, para, acto seguido, centrarse en la discusión legislativa y la forma en que puede ejercerse a cabalidad, reconociendo su existencia per se dentro del ordenamiento jurídico chileno. Para ello, se revisan la legislación nacional, desde la ley que crea dichos tribunales, y las leyes

lo hizo el 3 de julio de 2017. Mientras el Primer y el Tercer tribunales ambientales no fueron instalados, la competencia de estos quedó radicada en el Segundo Tribunal Ambiental, conforme a lo establecido en el artículo tercero transitorio de la ley ya señalada.

11 El 26 de octubre de 2009 se firmó un "Protocolo de acuerdo" entre algunos senadores y el Ejecutivo en el que se estableció el compromiso por parte del Gobierno para ingresar el proyecto de ley que los creó, cuyas funciones serían: “(a) actuar como órgano de control jurisdiccional de las decisiones de la Superintendencia; (b) resolver las controversias contenciosas administrativas en materia ambiental y (c) resolver las demandas por daño ambiental". Congreso Nacional de Chile. "Historia de la Ley n. ${ }^{\circ}$ 20.600, Crea los Tribunales Ambientales". [En línea]. Biblioteca del Congreso Nacional de Chile. Disponible en: https://www.bcn.cl/obtienearchivo?i $\mathrm{d}=$ recursoslegales/10221.3/37272/1/HL20600.pdf [Consultado el 27 de diciembre de 2018].

12 Plumer, M. C. Los tribunales ambientales: se completa la reforma a la institucionalidad ambiental. [En línea]. En Anuario de Derecho Público. 2013, n. ${ }^{\circ}$ 1, 297-315. Disponible en: http://derecho.udp.cl/wp-content/uploads/2016/08/013_Plumer.pdf [Consultado el 18 de diciembre de 2018].

13 Texto íntegro en Congreso Nacional de Chile. Protocolo de acuerdo proyecto de ley que crea el Ministerio y la Superintendencia del Medio Ambiente. [En línea]. Boletín 5947-12. 26 de octubre de 2009. Disponible en: http://www.uchile.cl/documentos/protocolo-de-acuerdoproyecto-de-ley-que-crea-el-ministerio-y-la-superintendencia-del-medio-ambiente_57732_3. pdf [Consultado el 27 de diciembre de 2018].

14 Ley n. 20.600 , art. 17. 
orgánicas de las instituciones con que interactúan, así como diversos casos del derecho comparado en donde el ius imperium se manifiesta expresamente.

Concluye el artículo demostrando la existencia y el ejercicio per se de esta facultad, y expresando la necesidad de adecuar las leyes a la institucionalidad ambiental.

\section{EL CONCEPTO DE IUS IMPERIUM O FACULTAD DE IMPERIO}

En doctrina existen muchas definiciones de la voz "imperio" o "imperium", desde la antigua Roma hasta hoy ${ }^{15}$.

Valeria Susana Guerra señala: "En primer lugar se debe señalar que en el origen etimológico, imperium deriva del verbo impero (-as, -are, -avi, -atum) que significa mandar, dar órdenes (como verbo transitivo), y regir, dominar, ejercer el mando, imperar (como verbo intransitivo). En español tenemos ambos significados en una sola palabra: ordenar" 16 .

Refleja el poder de quien ha sido encomendado por el poder superior para disponer lo apropiado para mantener el orden, contando con los recursos necesarios para que sus disposiciones se cumplan; estando facultado para aplicar la fuerza en caso de que no se obedezca lo dispuesto. La misma autora señala: "el imperium se refiere también a la fuerza o coerción para imponer la decisión, en este caso, judicial, y que en un primer momento va a ser facultad del magistrado. Así pues, el iudex privatus decidía a quién le asistía razón en una determinada contienda, siendo el magistrado el investido de imperium para hacer cumplir la disposición final" ${ }^{17}$.

Chamie ha definido esta facultad como "el poder jurídico para imponer normas, sanciones, hacer expropiaciones, imponer tributos y administrar recursos del Estado"18.

\section{EL EJERCICIO DEL IUS IMPERIUM POR PARTE DE DIVERSOS TRIBUNALES CHILENOS QUE NO PERTENECEN DIRECTAMENTE AL PODER JUDICIAL Y EN EL DERECHO COMPARADO}

Para afrontar el dilema respecto a los tribunales ambientales, se revisará el articulado pertinente de las diversas leyes constitutivas de otros tribunales

15 GUERRA, V. S. Imperium de las sentencias judiciales en Roma y en la actualidad. [En línea]. En Revista de Derecho Privado. 2011, n. ${ }^{\circ} 21,59-86$. Disponible en: http://www.scielo. org.co/scielo.php?script=sci_arttext\&pid=S0123-43662011000200004\&lng=en\&tlng=es [Consultado el 16 de febrero de 2018].

16 Ibíd.

17 Ibíd.

18 Снаміе, J. F. Imperium e Imperator. Origen del poder y sus proyecciones modernas. [En línea]. En Revista de Derecho Privado. Año 2011 n. ${ }^{\circ} 21,41-57$. Disponible en: http://www. scielo.org.co/scielo.php?script=sci_arttext\&pid=S0123-43662011000200003\&lng=en\&tlng=es [Consultado el 16 de febrero de 2018]. 
especiales en Chile, algunos de los cuales tienen atribuciones expresas y otros no, requiriendo entonces una interpretación armónica y extensiva.

\subsection{Tribunal de Propiedad Industrial}

Creado por la Ley 19.039, en los artículos 17 bis C y siguientes se define como "un órgano jurisdiccional especial e independiente, sujeto a la superintendencia directiva, correccional y económica de la Corte Suprema" ${ }^{19}$, radicando su competencia en las controversias relativas a las "invenciones en servicio" que regula el título vi de la misma ley $^{20}$. No se aprecia que este tribunal tenga regulación sobre la ejecución de las resoluciones, ni tampoco existe reenvío a otras normas que traten estas materias. La excepción la constituye el tratamiento de las "implicancias y recusaciones", caso en el cual se reenvía su regulación al Código Orgánico de Tribunales ${ }^{21}$, y en aquellos procedimientos para resolver materias precisas por el Jefe del Departamento de Propiedad Industrial, como tribunal de primera instancia -sin perjuicio de que aquel no es un tribunal propiamente tal- ${ }^{22-23}$. En todos estos casos se reenvía a la regulación pertinente del Código Orgánico de Tribunales y del Código de Procedimiento Civil ${ }^{24}$.

En otros casos, la ley reparte la competencia de diversas acciones a tribunales externos para su conocimiento y resolución ${ }^{25}$. No obstante, el Tribunal de Propiedad Industrial tiene restringida su facultad a ordenar la destrucción

19 Ley 19.039 , art. 17 bis C, inc. $1 .^{\circ}$.

20 Se alude a aquellas controversias que los trabajadores puedan tener con sus empleadores con ocasión de los contratos de trabajo y prestación de servicios cuya naturaleza sea el cumplimiento de una actividad inventiva o creativa. En estos casos la ley otorga la facultad de solicitar el registro, así como los eventuales derechos de propiedad industrial, al empleador o a quien encargó el servicio, salvo estipulación en contrario (art. 68 Ley 19.039).

21 Según el artículo 17 bis F de la Ley 19.039, “Los miembros del Tribunal estarán afectos a las causales de implicancia y recusación establecidas en los artículos 195 y 196 del Código Orgánico de Tribunales".

22 El artículo 17 de la Ley 19.039 le asigna al Jefe del Departamento de Propiedad Industrial el conocimiento de "[1] os juicios de oposición, los de nulidad de registro o de transferencias, los de caducidad, así como cualquiera reclamación relativa a su validez o efectos, o a los derechos de propiedad industrial [...] en general, ajustándose a las formalidades que se establecen en esta ley", y exige la fundamentación del fallo, que debe además cumplir con las formalidades del artículo 170 del Código de Procedimiento Civil, "en lo que sea pertinente".

23 Contra sus resoluciones procede apelación en ambos efectos, y contra las de segunda instancia procede recurso de casación en el fondo, ante la Corte Suprema.

24 Ley 19.039, art. 17 bis B.

25 Como sucede con el caso regulado en el artículo 51 bis B: "La solicitud para el otorgamiento de una licencia no voluntaria constituirá una demanda y deberá contener todos los requisitos del artículo 254 del Código de Procedimiento Civil. Conocerán de ella: [...] 3) En el caso del artículo $51, \mathrm{~N}^{\circ}$ 3, el juez de letras en lo civil, según las normas de competencia del Código de Procedimiento Civil y de acuerdo al procedimiento sumario". Lo mismo sucede en los artículos 51 bis D, 52, 67, 85 y 105 de la misma Ley 19.039 . 
de los elementos empleados para la falsificación o imitación de objetos con marcas falsificadas ${ }^{26}$, entre otros casos similares en la misma ley.

\subsection{Tribunales tributarios aduaneros}

Creados por la Ley 20.322, de 27 de enero de 2009, son "órganos jurisdiccionales letrados, especiales e independientes en el ejercicio de su ministerio" ${ }^{27}$, y tienen competencia respecto de diversas controversias producto de la relación entre los órganos del Estado y los contribuyentes, conforme al Código Tributario y otras leyes especiales ${ }^{28}$. Por reenvío expreso del artículo $1 .^{\circ}$ inciso final de su ley constitutiva, cuentan con amplia facultad de imperio, requiriendo el auxilio de la fuerza pública, quien no podrá calificar el fundamento, o la justicia o legalidad del decreto que se busca ejecutar ${ }^{29}$, ejerciendo el ius imperium sin mayores diferencias respecto de los tribunales pertenecientes al poder judicial.

\subsection{Tribunal de Contratación Pública}

Conoce de la impugnación contra actos u omisiones ilegales o arbitrarios, ocurridos en los procedimientos administrativos de contratación con organismos públicos regidos por la Ley $19.886^{[30]}$, que en sus artículos 22 y siguientes señala que se encuentra sometido a la superintendencia directiva, correccional y económica de la Corte Suprema ${ }^{31}$.

No es posible afirmar categóricamente si cuenta con ius imperium. Su articulado solo reenvía a las disposiciones comunes a todo procedimiento y a las normas del juicio ordinario para regular la ritualidad de la acción de impugnación, y solo en forma supletoria ${ }^{32}$. Asimismo, en cuanto a las normas

26 Artículo 29: “... En el caso de los utensilios o elementos utilizados, será facultad del juez competente decidir sobre su destino, pudiendo ordenar su destrucción o distribución benéfica".

27 Ley 20.322 , art. $1 .^{\circ}$, inc. $1 .^{\circ}$.

28 Ley 20.322 , nums. $1 .^{\circ}$ a $9 .^{\circ}$.

29 "Para hacer ejecutar sus sentencias y para practicar o hacer practicar las actuaciones que decreten, podrán los tribunales requerir de las demás autoridades el auxilio de la fuerza pública que de ellas dependiere, o los otros medios de acción conducentes de que dispusieren [...] La autoridad legalmente requerida deberá prestar el auxilio, sin que le corresponda calificar el fundamento con que se le pide ni la justicia o legalidad de la sentencia o decreto que se trata de ejecutar" (Ley 20.322, art. 1. ${ }^{\circ}$, inc. final).

30 Ley 19.886 , art. 24, inc. $1 .^{\circ}$.

31 No obstante, no pertenece al poder judicial.

32 Su artículo 27 señala: "La acción de impugnación se tramitará de acuerdo con las normas contenidas en este Capítulo [...]. Supletoriamente, se aplicarán las disposiciones comunes a todo procedimiento establecidas en el Libro I del Código de Procedimiento Civil y las del juicio ordinario civil de mayor cuantía que resulten conformes a la naturaleza breve y sumaria de este procedimiento". 
del juicio ordinario, el reenvío se restringe a las disposiciones apropiadas a la naturaleza breve y sumaria del procedimiento.

Este caso requiere interpretar extensivamente el artículo 27 de su ley constitutiva, entendiendo que entre las disposiciones comunes del Código de Procedimiento Civil se encuentran las relativas a la ejecución de las resoluciones, en el entendido de que cuesta concebir la existencia de un tribunal que no esté facultado para hacer cumplir lo resuelto, ya sea por sí o indirectamente.

\subsection{Tribunal de Defensa de la Libre Competencia}

Regulado en la Ley 19.911, de 14 de noviembre de 2003, en su título II, artículos 7. ${ }^{\circ}$ y siguientes, es definido como "un órgano jurisdiccional especial e independiente, sujeto a la superintendencia directiva, correccional y económica de la Corte Suprema, cuya función será prevenir, corregir y sancionar los atentados a la libre competencia" 33 .

Los artículos $17 \mathrm{~J}$ y $17 \mathrm{M}$ inciso primero le confieren amplias facultades de imperio. En efecto, puede decretar medidas cautelares judiciales y prejudiciales, reenviando su ejecución a los títulos IV y v del libro II del Código de Procedimiento Civil, salvo excepciones expresas, en lo que resultaren aplicables ${ }^{34}$, y en todo aquello en que no sean compatibles con aquel ${ }^{35}$.

El artículo $19 \mathrm{M}$ confirma el ius imperium de este tribunal, en cuanto la ejecución de lo que resuelva le corresponde directamente, contando con todas las facultades propias de un tribunal de justicia ${ }^{36}$, pudiendo por tanto apremiar a los condenados, sin forma de juicio, conforme a lo que dispone el artículo 543 del Código de Procedimiento Civil ${ }^{37}$.

\subsection{Derecho comparado}

El derecho comparado es más bien heterogéneo. Hay países que no cuentan con tribunales ambientales especializados, otros que cuentan con tribunales con un carácter más bien ético, y otros en donde existen tribunales o cortes ambientales dotados de ius imperium y no dotados con esta facultad ${ }^{38}$.

33 Ley 19.911 , art. $7 .^{\circ}$, inc. $1 .^{\circ}$.

34 El inciso final del artículo $17 \mathrm{~J}$ de la Ley 19.911 señala: "Sin perjuicio de lo dispuesto en los incisos precedentes, no regirá respecto de las medidas prejudiciales y precautorias que dicte el Tribunal lo establecido en los Títulos Iv y v del Libro II del Código de Procedimiento Civil, salvo lo señalado en los artículos 273, 274, 275, 276, 277, 278, 284, 285, 286, 294, 296 y 297 de dicho cuerpo legal, en cuanto resultaren aplicables".

35 Ley 19.911, art. $17 \mathrm{~N}$.

36 Ley 19.911, art. $17 \mathrm{M}$, inc. primero.

37 Ley 19.911 , art. $17 \mathrm{M}$, inc. segundo.

38 Frochisse, J. M. y Alanis, G. Tribunales ambientales. Toda persona tiene derecho a gozar de un medio ambiente sano. [En línea]. Centro de Estudios Jurídicos Ambientales (CEJA). 
Comenzando por América, en Canadá, Frochisse et al. ${ }^{39}$ describen al menos seis tribunales que "emplean algún Medio Alternativo de Solución de Conflictos Ambientales: el Tribunal de Apelación Ambiental de Alberta, la Junta del Medio Ambiente de Manitota, la Junta de Apelación de Evaluación del Impacto Ambiental de Ontario, la Junta de Energía de Ontario, la Junta de Audiencias Públicas Ambientales de Québec y la Junta de Evaluación Ambiental de Nueva Escocia"40.

En Estados Unidos no existen tribunales ambientales propiamente tales ${ }^{41}$, ya que la Agencia de Protección Ambiental (EPA, por su sigla en inglés), perteneciente al gobierno federal, cuenta con sus propios tribunales internos de reclamación administrativa ambiental, integrados por jueces independientes del área de fiscalización del mismo organismo, que conocen en doble instancia de las reclamaciones en contra de las resoluciones de dicho organismo fiscalizador - dotado con facultad de imperio-. Sus sentencias de segunda instancia pueden ser revisadas en la justicia ordinaria por la corte de apelaciones del circuito competente y, eventualmente, por la Suprema Corte ${ }^{42}$.

En Europa existe un Tribunal Europeo del Medio Ambiente, tribunal ético no gubernamental sin fines de lucro que no dicta sentencias, sino que básicamente organiza conversatorios y debates sobre problemáticas de materia ambiental, invitando a personalidades de distintos grupos y rescatando argumentos y soluciones para proteger y defender el medio ambiente ${ }^{43}$.

En ciertos países del Viejo Continente, como Suecia, existen cortes regionales ambientales, que promueven la aplicación de un código ambiental; conocen asuntos relacionados con agua, operaciones ambientales, daños y su reparación, y consideran el recurso ante la Corte Suprema, en última instancia ${ }^{44}$.

En Pakistán e India también existen tribunales ambientales. En Pakistán, conocen de asuntos ambientales por vía de diversos recursos que la ley les ha proveído dentro de la esfera de sus atribuciones. En India existe el National Green Tribunal, dotado con ius imperium, que ha dictado sentencias ordenando la imposición de cuantiosas multas a los responsables ${ }^{45}$. La Suprema

México, 2008. Disponible en: http://ceja.org.mx/IMG/pdf/Tribunales.pdf [Consultado el 2 de marzo de 2018].

39 Ibíd.

40 Ibíd.

41 Ibíd.

42 Conforme a la experiencia recogida por el suscrito durante el "Environmental Litigation and Adjudication Study Tour for Environmental Judges", organizado por la EPA en septiembre de 2014.

43 Frochisse y Alanis. Tribunales ambientales, cit.

44 Ibíd.

45 Tal como puede verse en el caso Mehta v. Union of India, de 2016. National Green Tribunal of India. Caso Mehta v. Union of India, sentencia del 23 de agosto de 2016. [En línea]. Disponible en: https://drive.google.com/file/d/0BzXilfcxe7yuYVpFstZyntmyN1E/view [Consultado el 2 de marzo de 2018]. 
Corte de India, en sus fallos de naturaleza ambiental, ha ordenado a estados o municipios la implementación de medidas inmediatas para reparar el daño ocasionado a ríos por desechos no tratados ${ }^{46}$.

En el caso de Nueva Zelanda, la Ressources Management Amendment Act de 1996 creó una Corte de Medio Ambiente itinerante: es así como los jueces se trasladan a los diversos puntos del país para resolver las controversias. En Australia, el Estado de New South Wales cuenta con el Tribunal de Tierras y Medio Ambiente ${ }^{47}$. Pring y Pring ${ }^{48}$ señalan que en Australia, Nueva Zelanda y Kenya existe un amplio enforcement incluyendo dentro de sus competencias la jurisdicción criminal, civil y administrativa. Especial atención les merece a estos autores el análisis del caso de Kenya, donde a los tribunales ambientales se les otorga facultad de imperio en el texto de la Carta Constitucional.

De acuerdo con diversos magistrados, según Pring y Pring, una buena práctica sería que los tribunales ambientales condensaran todas las materias relacionadas con el medio ambiente, de manera que pudieran aspectos tales como humedales, derechos de aguas y otros aspectos relacionados, el uso del territorio y el impacto de dichas normativas y las decisiones en virtud de ellas en un área afectada; así como que contaran con competencia en la adjudicación en asuntos civiles, criminales o administrativos, frecuentemente incorporando más de uno de ellos o los tres. La inclusión de la jurisdicción de asuntos criminales ambientales -tales como la pesca y la caza ilegales y el tráfico de especies salvajes-es clave para lograr la justicia ambiental y el desarrollo sustentable ${ }^{49}$.

Finalmente, en Latinoamérica destaca el caso de Costa Rica, en donde existe un Tribunal Ambiental Administrativo, órgano desconcentrado del Ministerio de Ambiente y Energía, creado el 4 de octubre de 1995 por la Ley Orgánica del Ambiente. Sus objetivos principales son prevenir, establecer, compensar y sancionar por daños al medio ambiente. Tiene competencia amplia para conocer y resolver, dentro del ámbito de la administración, ya sea de oficio o por denuncia, todas las violaciones contra la legislación ambiental que se cometan, conforme a un procedimiento ordinario que concluirá con una sentencia. Su actuación se rige por la oralidad, oficiosidad, celeridad e inmediación de la prueba. Puede impulsar de oficio el proceso, e incluso ordenar inspecciones in situ con el apoyo técnico que se requiera en cada caso ${ }^{50}$.

46 Tal como puede verse en el caso Mehta v. Union of India (Kanpur Tanneries). Supreme Court of India. Caso Mehta v. Union of India (Kanpur Tanneries), sentencia de 1988. [En línea]. Disponible en: http://www.globalhealthrights.org/asia/m-c-mehta-v-union-of-india-kanpurtanneries/ [Consultado el 2 de marzo de 2018].

47 Frochisse y Alanis. Tribunales ambientales, cit.

48 Pring y PRING. Environmental Courts and Tribunal Study and Global Environmental Outcomes LLC. A Guide for Policy Makers. [En línea]. Nairobi, Kenya: UN Environment, Law Division. Septiembre de 2016. [Consultado el 9 de enero de 2019]. Disponible en: https://wedocs. unep.org/bitstream/handle/20.500.11822/10001/environmental-courts-tribunals.pdf?sequence $=1$

49 Ibíd., 48.

50 Rojas, H. y García, M. E. Rol del Tribunal Ambiental Administrativo: protección y 
Si bien la creación de este tribunal ha tenido buena aceptación de la comunidad, su actuación se ha visto menguada por motivos de capacidad operativa frente al volumen de causas que le ha tocado conocer ${ }^{51}$. En 2008, a 11 años de su entrada en funcionamiento, su personal se encontraba compuesto de "seis abogados, dos ingenieros, un administrador, una secretaria y un chofer que laboran a tiempo completo y son nombrados por el Régimen de Servicio Civil" ${ }^{52}$. En esa época, Rojas y García ya lo habían señalado ${ }^{53}$, así como también el esfuerzo legislativo para paliar esta circunstancia ${ }^{54}$ que se ha prolongado hasta 2018 , lo que no le ha impedido, sin embargo, desarrollar aún mejor sus funciones ${ }^{55}$.

Finalmente, la recientemente creada Jurisdicción Ambiental del Salvador, también cuenta con facultades de imperio ${ }^{56}$.

\section{FUENTE DEL IUS IMPERIUM DE LOS TRIBUNALES AMBIENTALES CHILENOS}

\subsection{Antecedentes en la historia de la Ley 20.600}

La Ley 20.600 nace del protocolo de acuerdo firmado en octubre de 2009, que permitió aprobar el proyecto de reforma a la institucionalidad ambiental.

prevención en materia ambiental. [En línea]. Revista de Ciencias Económicas. 2008, vol. 26, n. ${ }^{\circ}$ 1,91-113. Disponible en: https://revistas.ucr.ac.cr/index.php/economicas/article/view/7158/6839 [Consultado el 7 de enero de 2019].

51 Frochisse y Alanis. Tribunales ambientales, 4.

52 Rojas y García. Rol del Tribunal Ambiental Administrativo, cit., 94.

53 Ibíd., 94.

54 "[L]os mismos legisladores en pleno de la Comisión Especial del Ambiente han reconocido el gran aporte y trabajo que está realizando al presentar un plan de ley que busca dotar de más recursos a este órgano, contemplando más equipo y personal; además de reconocer un mayor estatus legal, con el fin de equipararlo a un Tribunal Fiscal Administrativo o un Tribunal Aduanero; debido a que en los últimos tiempos han incrementado considerablemente las denuncias ambientales a las que debe dar seguimiento". Ibíd., 95.

55 Agullar, B. et al. Justicia ambiental en Costa Rica. Democracia política, económica, ecológica y conflictos socioambientales. Análisis N. ${ }^{\circ}$ 6-2018. [En línea]. Friedrich-Ebert Stiftung. Mayo de 2018. Disponible en: http://library.fes.de/pdf-files/bueros/fesamcentral/14519. pdf [Consultado el 7 de enero de 2019].

56 Véase Corte Suprema de Justicia de El Salvador. Juzgado Ambiental San Salvador realiza 16 diligencias en primeros 5 meses de funcionamiento. [En línea]. Dirección de Comunicaciones y Relaciones Públicas. Boletín Informativo. Mayo de 2015. Disponible en: http://www. csj.gob.sv/Comunicaciones/2015/MAY_15/BOLETINES/11.05.15_BOLAMB.pdf [Consultado el 13 de marzo de 2018]; Asamblea Legislativa de la República de El Salvador. Decretos n. ${ }^{\circ} 684$, n. ${ }^{\circ}$, n. ${ }^{\circ} 172$, n. ${ }^{\circ} 215$, n. 535 y n. ${ }^{\circ}$ 574. [En línea]. Disponibles en: http://www.csj.gob.sv/Comunicaciones/2017/03_MARZO/IMAGES/MA/Decreto\%20Legislativo\%20684\%20-Creaci\%C3\%B3n\%20 Juzgados\%20Ambientales.pdf [Consultado el 13 de marzo de 2018]; Aliven LizAma, S. La jurisdicción ambiental de El Salvador. [En línea]. El Salvador: El Salvador.com, edición digital de El Diario de Hoy. Abril de 2017. Disponible en: http://www.elsalvador.com/opinion/editoriales/335900/la-jurisdiccion-ambiental-de-el-salvador/ [Consultado el 13 de mayo de 2018]. 
Durante su tramitación se sostuvo que el proyecto inicial brindaba a la $\mathrm{Su}$ perintendencia amplios poderes de fiscalización y sanción, y que se requería un órgano que revisara sus decisiones ${ }^{57}$. Además, según Cordero ${ }^{58}$, "existía en muchos sectores la sensación de que las Cortes no estaban resolviendo adecuadamente los casos ambientales, porque desconocían el Derecho Ambiental o bien porque no estaban preparadas para resolver asuntos técnicos".

Durante el proceso legislativo, el proyecto de ley explicitaba las facultades de imperio de los tribunales ambientales. Sin embargo, diversas indicaciones parlamentarias y del gobierno dieron como resultado su redacción actual, más sintética y escueta, oyéndose la opinión de los diversos expertos en derecho procesal que fueron invitados a las comisiones legislativas ${ }^{59}$. Inicialmente, el artículo 29 del proyecto de ley decía:

La ejecución de las resoluciones pronunciadas en virtud de este procedimiento, corresponderá directamente al Tribunal Ambiental[,] el que contará, para tales efectos, con todas las facultades propias de un Tribunal de Justicia [...]. Las multas confirmadas o modificadas por el Tribunal Ambiental deberán pagarse dentro de los diez días hábiles siguientes a la fecha en que quede ejecutoriada la respectiva resolución. [...] Si cumplido el plazo el afectado no acreditare el pago de la multa, el Tribunal deberá, de oficio o a petición de parte, y sin forma de juicio, apremiarlo del modo establecido en el artículo 543 del Código de Procedimiento Civil ${ }^{60}$.

Posteriormente, la historia de la ley registra la indicación 39, del Gobierno, que modificó el proyecto en su totalidad. El nuevo texto decía en su artículo 62: "La ejecución de las resoluciones pronunciadas en virtud de la presente ley, corresponderá directamente al Tribunal Ambiental, el que contará, para tales efectos, con todas las facultades derivadas de su calidad de Tribunal Ordinario de Justicia...."61.

Luego, la indicación 40, de la senadora Alvear, proponía la siguiente redacción al artículo 42 del proyecto original: "Cumplimiento de resoluciones. Para hacer ejecutar sus resoluciones, el Tribunal podrá impartir órdenes directas a la fuerza pública o ejercer los medios de acción que estimare legalmente procedentes" ${ }^{2}$. Sin embargo, esta indicación sería retirada.

57 Cordero, L. Tribunales ambientales. [En línea]. En El Mercurio Legal. 20 de enero de 2012. Disponible en: http://www.elmercurio.com/Legal/Noticias/Analisis-Juridico/2012/01/20/ Tribunales-Ambientales aspx\# [Consultado el 6 de enero de 2019].

58 Ibíd., 1.

59 Congreso Nacional de Chile. "Historia de la Ley n. ${ }^{\circ} 20.600$, Crea los Tribunales Ambientales". [En línea]. Biblioteca del Congreso Nacional de Chile. Disponible en: https://www. bcn.cl/obtienearchivo?id=recursoslegales/10221.3/37272/1/HL20600.pdf [Consultado el 27 de diciembre de 2018].

60 Ibíd., mensaje.

61 Ibíd., indicación 39 del Ejecutivo.

62 Ibíd., indicación 40 de la Honorable senadora Alvear. 
De las razones de estas indicaciones, lamentablemente, no existe mayor registro que las actas de las comisiones legislativas, que han servido de base para este trabajo, no hallándose mayor información de antecedentes que puedan ser citados para contextualizar estos cambios en la redacción.

Finalmente, el texto definitivo nada dijo sobre el ius imperium, como se verá en el siguiente acápite.

\subsection{Fuente del ius imperium en la Ley 20.600}

En Chile, el ius imperium ${ }^{63}$ encuentra su fuente en los artículos 45 y 47 de la Ley 20.600 , reenviando respecto de sus vacíos a los libros primero y segundo del Código de Procedimiento Civil, cuyas disposiciones deben aplicarse en forma restringida, primando lo expresamente regulado en la ley ${ }^{64}$. No obstante, la supletoriedad no debe aplicarse a rajatabla, debiendo interpretarse restrictivamente, considerando en ello las instituciones y principios del derecho ambiental al momento de resolver las antinomias que puedan generarse ${ }^{65-66}$.

Para ejercer el ius imperium respecto de las instituciones parte de la fuerza pública y otras también requeridas por un tribunal ambiental, bastará un oficio, en algunos casos requiriendo el auxilio de la fuerza pública para hacer cumplir lo ordenado, o comisionando a alguna institución el aseguramiento del sitio amagado por la acción dañosa -medidas cautelares prejudiciales o judiciales-, o recabando mayores antecedentes de carácter científico; incluso bajo la forma de medidas para mejor resolver. Aquí es donde se presenta el problema de determinar si la orden del tribunal puede ejecutarse por dichas instituciones, conforme a su propia normativa orgánica.

A poco más de un lustro de la instalación de estos tribunales, es preciso socializar la aplicación de la normativa con las instituciones destinatarias de estos requerimientos, creando protocolos de acción que establezcan las contrapartes técnicas, las unidades respectivas que brindarán este apoyo, los

63 Ver punto 2 de este trabajo.

64 Ley 20.600, que crea los tribunales ambientales, art. 45.

65 Al respecto, el voto disidente de la Resolución de 5 de febrero de 2018, Causa Rol D-342018 del Tercer Tribunal Ambiental, rolante a foja 28, señala: "las disposiciones comunes a todo procedimiento, aplicables en forma supletoria a los procedimientos de la Ley $n .{ }^{\circ} 20.600$, deben releerse a la luz de los principios del Derecho Ambiental, a fin de evitar consecuencias irreparables producto de un proceso en plena ejecución que aparece prudente pausar [...] hasta que no se alleguen a este Tribunal los antecedentes necesarios que justifiquen su renovación por un nuevo plazo prudente o su caducidad; sin perjuicio de lo que eventualmente se resuelva en definitiva" (voto disidente en causa Rol D-34-2018, Resolución de 5 de febrero de 2018, a foja 28).

66 Tales como los principios preventivo y precautorio, y otros nacidos de las declaraciones de Estocolmo y de Río de Janeiro, o de la Convención sobre Diversidad Biológica, entre otros. Véase Puschel, L. y Urrutia, O. Principios del derecho internacional ambiental. [En línea]. Pontificia Universidad Católica de Valparaíso. Disponible en: http://ocw.pucv.cl/cursos-1/ derecho-ambiental-internacional/materiales-de-clases-1/catedras/clase-3/clase-3-principios-delderecho-internacional-ambiental-apuntes [Consultado el 12 de enero de 2019]. 
plazos mínimos y máximos de respuesta, las vías idóneas de comunicación, y las demás cuestiones que surjan.

\subsection{Reenvío y supletoriedad de las normas del Código de Procedimiento Civil}

El reenvío que regula el artículo 47 ya mencionado, debe aplicarse a la ritualidad y a los fines perseguidos al crear la ley de tribunales ambientales. El título XIX del libro I del Código de Procedimiento Civil, "De la ejecución de las resoluciones", regula el modo de cumplirlas en los artículos 238 y 240. El artículo 238 confiere al juez de la causa la facultad de dictar las medidas conducentes a dicho cumplimiento, considerando para ello la imposición de multas que no excedan de una unidad tributaria mensual ${ }^{67}$ y el arresto hasta por dos meses, debiendo aplicarse en forma prudencial ${ }^{68}$. Por otro lado, el artículo 240 faculta al tribunal para dejar sin efecto lo obrado en contravención a lo ejecutado una vez cumplida una resolución. Asimismo, configura en su segunda parte el delito de desacato, que se castiga con la pena de reclusión menor en su grado medio a máximo ${ }^{69}$.

\section{RAZONABILIDAD Y PROPORCIONALIDAD EN EL EJERCICIO DE ESTAS FACULTADES}

El ejercicio de las facultades de imperio debe ser acertado, y los tribunales velarán por que con ello no se vulneren las garantías de los ciudadanos más allá de lo que permite el ordenamiento jurídico.

Cuando hablamos de razonabilidad, nos referimos a la sujeción a ciertos estándares que impidan o disminuyan al máximo la arbitrariedad en la sanción a aplicar $^{70}$. Estas medidas deben aplicarse en forma gradual y proporcional a la

67 Aproximadamente 70 dólares de Estados Unidos a diciembre de 2018.

68 “... Cuando se trate del cumplimiento de resoluciones no comprendidas en los artículos anteriores, corresponderá al juez de la causa dictar las medidas conducentes a dicho cumplimiento, pudiendo al efecto imponer multas que no excedan de una unidad tributaria mensual o arresto hasta de dos meses, determinados prudencialmente por el tribunal, sin perjuicio de repetir el apremio" (Código de Procedimiento Civil o, art. 238).

69 “... Cumplida una resolución, el tribunal tendrá facultad para decretar las medidas tendientes a dejar sin efecto todo lo que se haga en contravención a lo ejecutado. El que quebrante lo ordenado cumplir será sancionado con reclusión menor en su grado medio a máximo" (Código de Procedimiento Civil, art. 240).

70 La exigencia propia del principio de razonabilidad, en abstracto, promueve "que la producción de derecho debe sujetarse a ciertos estándares que impidan o disminuyan al máximo la arbitrariedad". Arnold, R.; Martínez Estay, J. I. y ZúÑIga Urbina, F. El principio de proporcionalidad en la jurisprudencia del Tribunal Constitucional. [En línea]. En Revista Estudios Constitucionales. Año 10, n. ${ }^{\circ} 1,2012,65-116$. Disponible en: https://scielo.conicyt.cl/ pdf/estconst/v10n1/art03.pdf [Consultado el 25 de enero de 2019]. 
infracción de que se trate; debiendo iniciar con la aplicación de multas, hasta llegar al arresto, teniendo en consideración la racionalidad en su aplicación.

Según el Tribunal Constitucional chileno, "la falta de una gradualidad en la aplicación de sanciones, entregando total libertad para aplicar una o más, vulnera el principio de proporcionalidad al no existir reglas suficientemente precisas para evitar la discrecionalidad en su aplicación por parte del juez"71.

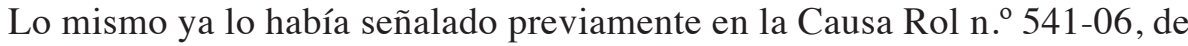
13 de julio de 2006, a propósito de la regulación legal de los derechos. Así, había concluido que "la regulación legal de los derechos 'debe ser razonable, no arbitraria, sirviendo como referencia del juicio de razonabilidad la concurrencia del principio de proporcionalidad, determinado por la relación coherente entre los medios utilizados y los fines legítimos perseguidos" 72 .

La aplicación desmedida de estas facultades puede desencadenar el ejercicio por parte del afectado de los medios que la Constitución Política le brinda, como lo es la interposición de un recurso de amparo, con base en que una orden de detención amenaza su libertad, resultando desproporcionada en su aplicación, cuando el tribunal dispone de otras medidas de menor intensidad para compeler al cumplimiento de lo resuelto ${ }^{73}$, y debiendo el arresto ser una medida de ultima ratio.

Según Nogueira,

... el principio de proporcionalidad se encuentra subsumido en el ordenamiento constitucional chileno en la garantía genérica de los derechos establecida constitucionalmente en las bases de la Institucionalidad [...] (artículos 6. ${ }^{\circ}$ y $\left.7 .^{\circ}\right)$, en el principio de prohibición de conductas arbitrarias (art. 19 N. ${ }^{\circ}$ 2) y en la garantía normativa del contenido esencial de los derechos (art. 19 N.$^{\circ} 26$ de la Constitución), además del valor justicia inherente al derecho. Puede entenderse también implícito en el art. 19 N. ${ }^{\circ} 3$, a propósito del derecho al debido proceso ${ }^{74}$.

Por otra parte, para Navarro, este principio se encuentra íntimamente vinculado con el principio de razonabilidad, en cuanto a "la adecuación cuantitativa entre la satisfacción de la finalidad pública perseguida y el contenido y el alcance de la decisión administrativa adoptada para tal efecto"75, que se

71 Navarro, E. Proporcionalidad y jurisprudencia del TC. [En línea]. En El Mercurio Legal. 13 de octubre de 2016. Disponible en: http://www.elmercurio.com/Legal/Noticias/ Analisis-Juridico/2016/10/13/Proporcionalidad-y-jurisprudencia-del-TC.aspx\# [Consultado el 25 de enero de 2018].

72 Sentencia Rol n. ${ }^{\circ}$ 541-06, del 13 de julio de 2006, considerando 15, en ArNold et al. El principio de proporcionalidad en la jurisprudencia del Tribunal Constitucional, cit., 87.

73 Por ejemplo, el auxilio de la fuerza pública o la imposición de multas a beneficio fiscal, u oficiar al Ministerio Público, para investigar un delito de desacato.

74 Nogueira (2009 y 2010) cit. en Arnold et al. El principio de proporcionalidad en la jurisprudencia del Tribunal Constitucional, cit.

75 NAVARRO, E. Notas sobre el principio de proporcionalidad en la reciente jurisprudencia 
logra mediante la ponderación de los medios a emplear, y "se complementa con el principio favor libertatis que promueve la adopción, entre todas las medidas posibles, de aquella que resulte ser menos restrictiva a la libertad de los particulares afectados" ${ }^{76}$. Supone un equilibrio entre el castigo impuesto y la conducta imputada ${ }^{77}$, donde la sanción que se aplique sea adecuada a la entidad de la infracción ${ }^{78}$. De este modo, "siempre la imposición de toda sanción $[\ldots]$ debe obedecer a razones objetivas previamente fijadas por el legislador y que se enmarquen adecuadamente dentro de un debido proceso" $" 79$.

Finalmente, una revisión de las disposiciones procesales chilenas en materia laboral ${ }^{80} \mathrm{o}$ de familia ${ }^{81}$ muestra que, en la práctica, la privación total de la libertad como medida de apremio, hoy ha derivado en reclusión nocturna en recintos especiales a cargo de Gendarmería de Chile; aplicándose en forma gradual y razonable, y velando por que sean proporcional a la infracción, conforme a la Convención Interamericana de Derechos Humanos, también conocida como "Pacto de San José de Costa Rica" ${ }^{2}$. Igual razonamiento se aprecia en nuestro proceso penal ${ }^{83} \mathrm{y}$ en el sistema penitenciario ${ }^{84}$, donde se persigue que la orden judicial desobedecida o la multa impaga sea hecha cumplir o satisfecha por la vía de la reclusión nocturna y no por la privación de la libertad en forma directa. Por otra parte, y tratándose del delito de

constitucional. [En línea]. En Revista de Derecho Público. 2018, n. ${ }^{\circ}$ especial, 309-322. Disponible en: https://revistas.uchile.cl/index.php/RDPu/article/download/51264/53680 [Consultado el $19 \mathrm{de}$ diciembre de 2018].

76 СамасHO (2010), cit. ibíd., 316.

77 NAVARRO. Notas sobre el principio de proporcionalidad en la reciente jurisprudencia constitucional, cit., 310, citando la sentencia del TC Rol 2922-15, 2015, considerando 19. .

78 Bermúdez (2011), cit. ibíd., 316.

79 Ibíd., 321.

80 El Código del Trabajo regula los apremios en los artículos 292 (negativa del empleador a cumplir la orden de reincorporación, o ante una nueva separación o no pago oportuno y debido de las remuneraciones y demás prestaciones laborales) y 471 (no pago de prestaciones como resultado de una sentencia ejecutoriada).

81 Ley 19.968, arts. 34 (arresto por no comparecencia del testigo), 77 (impedimento por los padres, personas responsables o cualquier otra persona de la ejecución de la medida acordada por el tribunal), 94 (incumplimiento de las medidas cautelares) y 95 (no comparecencia del denunciado o demandado).

82 Se percibe de su texto, como en el artículo 5.6: “... Las penas privativas de la libertad tendrán como finalidad esencial la reforma y la readaptación social de los condenados...".

83 El Código Procesal Penal consagró el principio de inocencia del imputado, y estableció un catálogo de medidas cautelares personales alternativas a la prisión preventiva, dejando la privación de libertad como último recurso (según los arts. $4 .^{\circ}, 5 .^{\circ}, 141$ lit. c inc. $2 .^{\circ}, 155,156$ y 157).

84 Reglamento de la Ley 18.216, artículo primero: "La ejecución de las penas privativas o restrictivas de libertad podrá sustituirse por el tribunal que las imponga, por alguna de las siguientes penas señaladas en el artículo $1 .^{\circ}$ de la Ley 18.216: a) Remisión condicional; b) Reclusión parcial; c) Libertad vigilada; d) Libertad vigilada intensiva; e) Expulsión, en el caso señalado en el artículo 34 de la Ley n. ${ }^{\circ} 18.216$, y f) Prestación de servicios en beneficio de la comunidad"; consagrando su fin resocializador. 
desacato, el Ministerio Público podría solicitar la privación de la libertad como resultado de una investigación por tal delito, donde la privación de la libertad podrá aplicarse como ultima ratio.

5. EJERCICIO DEL IUS IMPERIUM POR PARTE DE LOS TRIBUNALES AMBIENTALES CHILENOS RESPECTO DE DIVERSAS INSTITUCIONES DEL ESTADO

Una de las interrogantes que motivaron este trabajo fue la de si existen facultades para ejecutar las órdenes impartidas por los tribunales ambientales a las entidades estatales al ejercer su función jurisdiccional. El análisis de la legislación relacionada con la ejecución de las resoluciones se realiza a continuación.

\subsection{Ejercicio del ius imperium respecto de Carabineros de Chile}

La Ley n. ${ }^{\circ} 20.600$ concede implícitamente el ius imperium sobre dicha institución en el artículo 45, al referirse a la "fuerza pública". Por su parte, la Ley Orgánica de Carabineros la define como una "institución policial técnica y de carácter militar, que integra la fuerza pública" ${ }^{85}$.

Los tribunales ambientales podrán ordenar el resguardo policial, tanto del lugar como de quienes ejecuten lo dispuesto por la magistratura, la entrada y registro de lugares con facultades de allanamiento y descerrajamiento -en el contexto de una inspección personal de tribunal o una medida cautelar-, la aprehensión de una persona por el no cumplimiento de lo ordenado, o incluso el resguardo del recinto en que se vayan a llevar a cabo las audiencias programadas (todo ello en caso de que así fura requerido), con las mismas facultades de toda magistratura.

La misma ley orgánica antes señalada, en su artículo $4 .^{\circ}$, establece que dicha institución "prestará a las autoridades judiciales el auxilio de la fuerza pública que éstas soliciten en el ejercicio de sus atribuciones. [...] Deberá cumplir sin más trámite sus órdenes y no podrá calificar su fundamento, oportunidad, justicia o legalidad" 86 . Así, bastará oficiar para hacer cumplir lo resuelto, sea que se trate de paralización, cierre u otra medida cautelar, desplegando el apoyo requerido. Se excluyen los casos de autorización de medidas solicitadas por la Superintendencia de Medio Ambiente, que tienen su propia regulación, estando aquella dotada con potestades propias para hacerlas cumplir dentro de un procedimiento sancionatorio.

En atención a que los tribunales ambientales son relativamente recientes, deben establecerse protocolos para el despacho de estas órdenes, estableciendo

85 Ley Orgánica de Carabineros de Chile, art. 1. ${ }^{\circ}$, inc. $1 .^{\circ}$.

86 Ley Orgánica de Carabineros de Chile, art. 4.․․ 
responsables, formatos de documentos y vías de comunicación expeditas, y evitando así el envío inorgánico y desordenado de solicitudes; necesidad esta que no solo concurre respecto de Carabineros, sino también del resto de las instituciones, como más adelante se verá.

En lo que concierne al Primer ${ }^{87-88}$ y el Tercer Tribunal Ambiental, la relación con Carabineros ha sido colaborativa respecto de inspecciones personales que se han llevado a cabo $^{89}$; por su parte, el Segundo Tribunal Ambiental ha ejercido el ius imperium, requiriendo imperativamente el auxilio de la fuerza pública ${ }^{90}$.

\subsection{Ejercicio del ius imperium respecto de la Policía de Investigaciones de Chile}

La Ley Orgánica de la Policía de Investigaciones de Chile (PDI), en su artículo $1 .^{\circ}$, define a esta entidad como una institución "integrante de las fuerzas de orden", por lo que la fuente del ius imperium se encuentra indirectamente en la segunda parte del artículo 45 de la Ley 20.600, que debe interpretarse

87 Causa Rol R-6-2014, “Empresa Nacional de Electricidad S.A.con Superintendencia del Medio Ambiente" (Central Termoeléctrica "Bocamina", Coronel, Región del Biobío). En el acta de foja 944, de 18 de diciembre de 2014, se consigna: "Consultado a los carabineros acompañantes..." o "Carabineros informa que...", dando cuenta de una participación de acompañamiento al personal del tribunal. No obstante, en dicho expediente no constan oficios requiriendo auxilio para dicha diligencia. Tercer Tribunal Ambiental de Chile. Expediente electrónico correspondiente a la Causa Rol R-6-2014, "Empresa Nacional de Electricidad S.A. con Superintendencia del Medio Ambiente". [En línea]. Disponible en: https://causas.3ta.cl/causes/84/expedient/1413/?a ttachmentId=1832 [Consultado el 31 de Diciembre de 2018]

88 Causa rol R-1-2017: se contó con apoyo de Carabineros y de la Armada de Chile, sin que en el expediente se registren oficios ordenando su auxilio para la diligencia decretada.

89 En la inspección del Primer Tribunal Ambiental al proyecto Pascua Lama se contó con el apoyo de Carabineros; según se aprecia en Primer Tribunal Ambiental. Ministros del 1TA concluyen visita inspectiva a faena de Pascua Lama. [En línea]. Primer Tribunal Ambiental. Febrero de 2018. Disponible en: https://www.1 ta.cl/minitros-del-1ta-concluyen-visita-inspectivaa-faena-de-pascua-lama/ [Consultado el 9 de marzo de 2018].

90 En las causas D-06-2013 y D-15-2015: se ordenó el apoyo de la fuerza pública, oficiando al efecto a Carabineros de Chile, para el apoyo necesario durante la paralización de obras y retiro de maquinaria e implementos de trabajo. Fuente: Segundo Tribunal Ambiental de Chile. Expediente electrónico correspondiente a la Causa Rol D-06-2013, "Estado de Chile / Servicios Generales Larenas Ltda". [En línea]. Disponible en: http://consultas.tribunalambiental. cl/ambiental_portal/Web/Portal/LEX_POR_ExpedienteCausa.aspx?q=qwwvEXYDPdGeq/+h7eqnh xvezucluSU2Or+rO7HhUGjFJ6cmGnkZzf5/DkpTG2mвoJcpr7P04DLR1fsyZS8IgCP4xUFooyNiW3V9nyh9KEQ= [Consultado el 22 de febrero de 2018]; y Segundo Tribunal Ambiental de Chile. Expediente electrónico correspondiente a la Causa Rol D-15-2015, "Ilustre Municipalidad de Maipú / Minera Española Chile Limitada". [En línea]. Disponible en: http://consultas. tribunalambiental.cl/ambiental_portal/Web/Portal/LEX_POR_ExpedienteCausa.aspx?q=qwwvex YDPdGeq/+h7eqnh60vGLMqP+vfWI31+ENKYv3SdDaROavuPEBEYDMzAQ41Hv1RxDH6gXGr+ AfjAF5R+FAqgOgHmTh0/8Yj84Yj3w4= [Consultado el 22 de febrero de 2018]. 
extensivamente en su parte final ${ }^{91}$, donde faculta al tribunal para "ejercer los medios de acción que fueran legalmente procedentes".

El legislador dio a los tribunales ambientales la discrecionalidad para ejercer dichos medios de la forma más idónea para cumplir sus resoluciones, pudiendo disponer en este caso de la Policía de Investigaciones cuando se requiera, por ejemplo, mantener inalterable un sitio de suceso en caso de daño ambiental, llevar a cabo las pericias necesarias para la determinación de sus componentes, recabar la información que se le haya solicitado conforme a una medida provisional conservativa o innovativa, o para la búsqueda y detención de un infractor contumaz que no haya cumplido con el pago de la multa que el tribunal le haya impuesto -esto último conforme a la gradualidad previamente referida-.

Desde otra perspectiva, cuando el inciso primero del artículo 45 de la Ley 20.600 faculta a los tribunales ambientales para ejercer los medios de acción que fueren legalmente procedentes, si bien no se menciona a la PDI en su articulado, en una interpretación armónica puede entenderse que el tribunal puede escoger el medio de acción más idóneo para su cometido cuando persigue proteger el bien jurídico amenazado o afectado, según sea el caso, pudiendo ser la intervención de la PDI uno de estos medios.

La ley orgánica de aquella institución, en su artículo $4 . .^{\circ}$, indica que su misión fundamental es investigar los delitos, "sin perjuicio de las actuaciones que en virtud de la ley le corresponde realizar sin mediar instrucciones particulares de los fiscales"; lo que muestra la versatilidad de su actuar por disposición del legislador, entendiendo que "la ley" 92 no solamente es su ley orgánica, sino todo el ordenamiento jurídico. Incluso, el artículo $5 .^{\circ}$ de la misma ley orgánica en análisis indica que le corresponde dar cumplimiento, entre otras, "a las órdenes emanadas de las autoridades judiciales [...] y dar cumplimiento a otras funciones que le encomienden las leyes".

Es decir, ya sea desde el punto de vista de las órdenes emanadas del tribunal ambiental en su calidad de autoridad judicial, o de las "otras funciones" 93 que a la PDI le encomienden las leyes, es posible establecer el vínculo entre ambas instituciones; como ya ha ocurrido en ocasiones anteriores a propósito de la implementación de medidas cautelares conservativas.

El caso más claro fue conocido por el Tercer Tribunal Ambiental de Chile, donde en el marco de una acción por daño ambiental, en la causa Rol D-252017, "Ilustre Municipalidad de Pitrufquén con Empresa de Ferrocarriles del Estado y otros", originada por la caída de un puente ferroviario sobre el río Toltén, con vagones cargados con sustancias peligrosas, la PDI colaboró

91 Conforme a los artículos 19 al 24 del Código Civil, norma de derecho común, supletorio y de aplicación general a este respecto (nota del autor).

92 Ley Orgánica de la Policía de Investigaciones de Chile, art. 4.․

93 Ley Orgánica de la Policía de Investigaciones de Chile, art. 5.․ 
en la práctica de las inspecciones personales de fechas 10 de marzo y 6 de abril de 2017. En efecto, durante el proceso se ofició a la PDI requiriendo su participación con personal de la Brigada de Delitos del Medio Ambiente (BIDEMA) y se le reconoció su experticia como garante de la limpieza del proceso de extracción de dichos vagones ${ }^{94}$.

El concurso de aquella institución policial se logró gracias a un acercamiento en donde se analizó y maduró la idea de participación y colaboración. No obstante, y tal como se ha planteado respecto de Carabineros, es necesario un protocolo de actuación que establezca responsables y conductos regulares, a la espera de una adecuación legal de las leyes que regulan las instituciones involucradas.

\subsubsection{Prohibición de actuar de la PDI respecto de los tribunales civiles}

El artículo 7. e de la Ley Orgánica de la PDI contiene la prohibición de emplear a los funcionarios de la institución para el cumplimiento de las resoluciones judiciales de carácter civil, salvo que una ley expresamente así lo disponga ${ }^{95}$.

De su lectura puede surgir la tentación de hacer una interpretación simplista, concluyendo que todo aquello que no sea criminal es civil, incluidas las resoluciones de los tribunales especiales, en donde caben los tribunales ambientales. Por el contrario, existen diversos argumentos, tanto de fondo como prácticos, que excluyen a las órdenes de los tribunales ambientales de esta prohibición legal.

En primer lugar, desde ya hace mucho tiempo el derecho ambiental ha adquirido una identidad propia, con principios e instituciones que claramente lo distinguen, básicamente enfocados hacia la relación del hombre con el medio ambiente. Por otro lado, su objeto de estudio es la regulación dirigida

94 A foja 74 se ordena: "Previo a la remoción de cada vagón, la empresa comunicará tal acción con una anticipación de 48 horas a la Brigada Investigadora de Delitos contra el Medio Ambiente y Patrimonio Cultural, de Valdivia, de la Policía de Investigaciones de Chile. Sólo en presencia de funcionarios de dicho cuerpo policial, se podrán retirar los vagones para ubicarlos en lugar seguro para su inspección por éstos. Una vez concluido dicho examen, y previa autorización de la misma Policía, se podrán retirar los vagones y las sustancias en ellos contenidas, por las empresas encargadas de su disposición final". Asimismo, cuando ordena a la ENFE que, para "el retiro de la estructura dañada y que haya caído o colapsado sobre el río Toltén, debe comunicar tal acción con una anticipación de 48 horas a la Brigada Investigadora de Delitos contra el Medio Ambiente y Patrimonio Cultural, de Valdivia [...]. Sólo en presencia de funcionarios de dicho cuerpo policial, se podrá hacer su retiro y ubicarlos en lugar seguro para su inspección por estos [...] [P]revia autorización de la misma Policía, el material removido deberá ser transportado hasta un lugar apropiado"; confirmando la importancia de dicha institución y las facultades del tribunal para impartir instrucciones tendientes a asegurar la indemnidad del ambiente (nota del autor).

95 "Los funcionarios de la Institución no podrán ser empleados para el cumplimiento de resoluciones judiciales de carácter civil, salvo que una ley expresamente así lo disponga". Decreto Ley 2460, de 1979, Ley Orgánica de la Policía de Investigaciones, art. 7.․ 
hacia la protección y conservación de la diversidad biológica y de los recursos naturales renovables e hídricos, buscando el desarrollo sustentable ${ }^{96}$.

Por otra parte, la sola creación de esta jurisdicción especializada ha trasladado el conocimiento de la mayoría de estas causas desde los tribunales civiles ordinarios hacia esta magistratura ${ }^{97}$.

Finalmente, la Ley Orgánica de la PDI fue dictada cuando aún no existía una jurisdicción ambiental especializada, existiendo solo los juzgados de letras (civiles), los juzgados del crimen (penales) y algunos tribunales especiales como los juzgados de menores y del trabajo, y las restantes materias no penales eran absorbidas por la jurisdicción común de los juzgados de letras ${ }^{98}$. Más que hacer una exégesis de la norma, lo que se requiere es modificar su texto para adecuarla a los tiempos que hoy se viven.

A la luz de los argumentos expuestos, nos inclinamos por la postura según la cual los tribunales ambientales no se comprenden en la prohibición legal, por lo que la PDI se encuentra facultada para cumplir lo que dichos tribunales le requieran.

\subsection{Ejercicio del ius imperium respecto de Gendarmería de Chile}

La relación entre los tribunales ambientales y Gendarmería de Chile, a cargo del sistema penitenciario en nuestro país, se materializará en casos puntuales ante la aplicación de medidas de apremio -específicamente arresto- cuando quien debe cumplir una orden judicial sea contumaz. Bajo ninguna circunstancia, sin embargo, esto debe entenderse como la pena asignada a un delito ambiental, aún no regulados sistemáticamente en nuestro país. Al respecto, se ha afirmado que "no existen en la Ley n. ${ }^{\circ} 19.300$ ni en los restantes instrumentos ambientales, mecanismos de carácter penal establecidos directamente para sancionar a quienes causen un grave daño ambiental o burlen derechamente el Sistema de Evaluación de Impacto Ambiental, haciendo ilusorias sus finalidades" $"$.

96 CÁrCAMo, A. El derecho medio ambiental en Chile: sus profusas fuentes normativas; la antigua $\mathrm{v} / \mathrm{s}$ la nueva institucionalidad medio ambiental; $y$ los avances $\mathrm{v} / \mathrm{s}$ algunas cuestiones pendientes de resolver. [En línea]. Diario Constitucional. 12 de junio 2013. Disponible en: http://www.diarioconstitucional.cl/articulos/el-derecho-medio-ambiental-en-chile-sus-profusasfuentes-normativas-la-antigua-vs-la-nueva-institucionalidad-medio-ambiental-y-los-avances-vsalgunas-cuestiones-pendientes-de-resolver/ [Consultado el 6 de enero de 2019].

97 En virtud de la competencia de los tribunales ambientales (Ley 20.600, art. 17).

98 En 1979 solo existían los juzgados de letras del crimen, los juzgados de letras en lo civil, los juzgados de menores (creados por la Ley 16.618, en 1967) y de policía local (creados por la Ley 15.231, en 1963). Recién en 1986 serían creados los juzgados de letras del trabajo (Ley 18.510).

99 Matus Acuña, J. P. et al. Análisis dogmático del derecho penal ambiental chileno, a la luz del derecho comparado y las obligaciones contraídas por Chile en el ámbito del derecho internacional: conclusiones y propuesta legislativa fundada para una nueva protección penal 
La Ley Orgánica de Gendarmería de Chile indica que le corresponde a dicha institución "[c]umplir resoluciones emanadas de autoridad competente, relativas al ingreso y a la libertad de las personas sometidas a su guarda, sin que le corresponda calificar el fundamento, justicia o legalidad de tales requerimientos" ${ }^{100}$. Así, bastará la sola orden de arresto y apremio despachada por el tribunal ambiental para su ingreso, sin ser necesario que comparezca previamente ante dicha magistratura, para el ingreso del arrestado a alguna de sus dependencias.

\section{CONCLUSIONES}

En el Cono Sur, Chile ha sido el primer país en crear tribunales ambientales en la estructura multidisciplinaria, a nivel de jurisdicción especializada. Llama especialmente la atención, al respecto, su composición transdisciplinaria -abogados y licenciados en ciencias- que releva el rol del científico en el proceso de adjudicación, más allá del mero asesor, equiparándose al rango de sus integrantes que son abogados, en una rama en donde es el derecho el que se encuentra al servicio de la ciencia en la resolución de conflictos socioambientales.

Los tribunales ambientales cuentan con ius imperium, lo que significa que Carabineros, la PDI y Gendarmería de Chile no pueden cuestionar las órdenes que aquellos les impartan. Pese a la eliminación, durante la tramitación de la Ley 20.600, de la redacción expresa de esta facultad, su redacción sintética no implica una limitación de este poder, sino que es una aplicación de la supletoriedad del ordenamiento jurídico, en este caso desde una mirada ambiental, no obstante que la facultad de imperio tiene su fuente en el derecho procesal. Con todo, es preciso llegar a contar con instancias de coordinación entre aquellas instituciones y la autoridad judicial ambiental.

Las medidas de fuerza deben aplicarse en forma razonable y gradual por el tribunal, de manera que sean proporcionales al incumplimiento de que se trate, siendo el arresto una medida de ultima ratio. Entre otras consideraciones, por cuanto la aplicación de medidas desproporcionadas o arbitrarias puede terminar siendo estéril para los fines perseguidos.

En Chile, la experiencia ha resultado positiva en el ejercicio del ius imperium por parte de esta judicatura. La actitud colaborativa de las instituciones del Estado ha permitido el expedito desarrollo de las diligencias ordenadas por el tribunal cuando se les ha requerido, supliendo la falta de protocolos de acción mediante la coordinación previa con la autoridad de las labores a

del medio ambiente en Chile. [En línea]. En Ius et Praxis. 2003, vol. 9, n. 2, 11-57. Disponible en: https://scielo.conicyt.cl/scielo.php?script=sci_arttext\&pid=S0718-00122003000200002\&ln $\mathrm{g}=\mathrm{es} \& \mathrm{nrm}=$ iso [Consultado el 7 de enero de 2017].

100 Ley Orgánica de Gendarmería de Chile, art. 3., lit. b. 
desarrollar. No obstante, la Ley 20.600 adolece de vacíos en materia de interacción con las policías, vacíos también existentes en las leyes que regulan a estos organismos. Esta es una tarea pendiente del legislador, que puede inspirar a quienes se encuentren interesados en proponer las modificaciones que los textos legales orgánicos de las diversas instituciones requieran, para que su articulado reciba a las nuevas judicaturas especializadas que se han creado, y que van más allá de la dicotomía “civil-penal” existente al momento de su entrada en vigencia.

\section{REFERENCIAS}

\section{Doctrina}

Acevedo, C. y Torres, A. Determinación de la pena en Chile. Principios de un Estado democrático de derecho y fines de la pena. [En línea]. Tesis. Santiago: Universidad de Chile, 2009. Disponible en: http://repositorio.uchile.cl/handle/2250/106934 [Consultado el 25 de enero de 2018].

Agullar, B. et al. Justicia ambiental en Costa Rica. Democracia política, económica, ecológica y conflictos socioambientales. Análisis N. ${ }^{\circ}$ 6-2018. [En línea]. FriedrichEbert Stiftung. Mayo de 2018 Disponible en: http://library.fes.de/pdf-files/bueros/ fesamcentral/14519.pdf [Consultado el 7 de enero de 2019].

Aliven, S. La jurisdicción ambiental de El Salvador. [En línea]. El Salvador: El Salvador. com, edición digital de El Diario de Hoy. Abril de 2017. Disponible en: http://www. elsalvador.com/opinion/editoriales/335900/la-jurisdiccion-ambiental-de-el-salvador/ [Consultado el 13 de mayo de 2018].

Arnold, R.; Martínez, J. y Zúñiga., F. El principio de proporcionalidad en la jurisprudencia del Tribunal Constitucional. [En línea]. En Revista Estudios Constitucionales, Centro de Estudios Constitucionales de Chile Universidad de Talca. Año 10, n. ${ }^{\circ} 1$, 2012, 65-116. Disponible en: https://scielo.conicyt.cl/pdf/estconst/v10n1/art03.pdf [Consultado el 25 de enero de 2019].

BARros, C. et al. Las medidas cautelares innominadas. El poder del juez en el medioambiente. [En línea]. Revista de Derecho Procesal Contemporáneo. Semilleros de Derecho Procesal. Año 2016, n. ${ }^{\circ}$ 2, 10-40. Disponible en: http://publicacionesicdp.com/index. $\mathrm{php} / \mathrm{revista-semilleros-icdp/article/download/415/423} \mathrm{[Consultado} \mathrm{el} 18$ de diciembre de 2018].

Bhattacharjee, A. ngt orders Delta Group to pay environmental compensation of 100 crores; Adani Group to pay 5 Crores [Read Judgment]. [En línea]. Live Law. Agosto de 2016. Disponible en: http://www.livelaw.in/ngt-orders-delta-group-pay-environmentalcompensation-100-crores-adani-group-pay-5-crores/ [Consultado el 2 de marzo de 2018].

CÁrcamo, A. El derecho medio ambiental en Chile: sus profusas fuentes normativas; la antigua $\mathrm{v} / \mathrm{s}$ la nueva institucionalidad medio ambiental; y los avances $v / \mathrm{s}$ algunas cuestiones pendientes de resolver. [En línea]. En Diario Constitucional. 12 de junio de 2013. Disponible en: http://www.diarioconstitucional.cl/articulos/el-derecho-medioambiental-en-chile-sus-profusas-fuentes-normativas-la-antigua-vs-la-nueva-institucio- 
nalidad-medio-ambiental-y-los-avances-vs-algunas-cuestiones-pendientes-de-resolver/ [Consultado el 6 de enero de 2019].

Chamie, J. Imperium e Imperator. Origen del poder y sus proyecciones modernas. [En línea]. En Revista de Derecho Privado. Año 2011, n. ${ }^{\circ} 21,41-57$. Disponible en: http:// www.scielo.org.co/scielo.php?script=sci_arttext\&pid=S0123-43662011000200003\&ln $\mathrm{g}=$ en\&tlng=es [Consultado el 16 de febrero de 2018].

Cordero, L. Tribunales ambientales. [En línea]. En El Mercurio Legal, Chile. 20 de enero de 2012. Disponible en: http://www.elmercurio.com/Legal/Noticias/AnalisisJuridico/2012/01/20/Tribunales-Ambientales.aspx\# [Consultado el 6 de enero de 2019].

Corte Suprema de Justicia de El Salvador. Juzgado Ambiental San Salvador realiza 16 diligencias en primeros 5 meses de funcionamiento. [En línea]. En Dirección de Comunicaciones y Relaciones Públicas. Boletín Informativo. Mayo de 2015. Disponible en: http://www.csj.gob.sv/Comunicaciones/2015/MAY_15/BOLETINES/11.05.15_вOLAMB. pdf [Consultado el 13 de marzo de 2018].

Costa, E. Special Administrative Courts in Chile. [En línea]. En Revista de Derecho, Valdivia. Año 2014, vol. 27, n. ${ }^{\circ}$ 1, 151-167. Disponible en: https://scielo.conicyt.cl/ scielo.php?script=sci_arttext\&pid=S0718-09502014000100007\&lng=es\&nrm=iso [Consultado el 18 de diciembre de 2018].

Frochisse, J. y Alanis, G. Tribunales ambientales. Toda persona tiene derecho a gozar de un medio ambiente sano. [En línea]. Centro de Estudios Jurídicos Ambientales (CEJA). México, 2008. Disponible en: http://ceja.org.mx/IMG/pdf/Tribunales.pdf [Consultado el 2 de marzo de 2018].

GUERra, V. Imperium de las sentencias judiciales en Roma y en la actualidad. [En línea]. En Revista de Derecho Privado. 2011, n. ${ }^{\circ}$ 21, 59-86. Disponible en: http://www.scielo. org.co/scielo.php?script=sci_arttext\&pid=S0123-43662011000200004\&lng=en\&tlng $=$ es [Consultado el 16 de febrero de 2018].

Matus, J. P. et al. Análisis dogmático del derecho penal ambiental chileno, a la luz del derecho comparado y las obligaciones contraídas por Chile en el ámbito del derecho internacional: conclusiones y propuesta legislativa fundada para una nueva protección penal del medio ambiente en Chile. [En línea]. En Ius et Praxis. 2003, vol. 9, n. ${ }^{\circ}$, 11-57. Disponible en: https://scielo.conicyt.cl/scielo.php?script=sci_arttext\&pid=S071800122003000200002\&lng=es\&nrm=iso [Consultado el 7 de enero de 2017].

Minaverry, C. El avance de la implementación de los tribunales ambientales en América Latina. [En línea]. En Gestión y Ambiente. 2015, vol. 18, n. 2, 95-108. Disponible en: https://revistas.unal.edu.co/index.php/gestion/article/view/49367 [Consultado el 2 de marzo de 2018].

Náquira, J. et al. Principios y penas en el derecho penal chileno. [En línea]. En Revista Electrónica de Ciencia Penal y Criminología. 2008, n. ${ }^{\circ}$ 10, r2:1-r2:71. Disponible en: http://criminet.ugr.es/recpc/10/recpc10-r2.pdf [Consultado el 25 de enero de 2018].

Navarro, E. Proporcionalidad y jurisprudencia del TC. [En línea]. En El Mercurio Legal. 13 de octubre de 2016. Disponible en: http://www.elmercurio.com/Legal/Noticias/ Analisis-Juridico/2016/10/13/Proporcionalidad-y-jurisprudencia-del-TC.aspx\# [Consultado el 25 de enero de 2018]. 
NAVARRo, E. Notas sobre el principio de proporcionalidad en la reciente jurisprudencia constitucional. [En línea]. En Revista de Derecho Público. 2018, n. ${ }^{\circ}$ especial, 309-322. Disponible en: https://revistas.uchile.cl/index.php/RDPU/article/download/51264/53680 [Consultado el 19 de diciembre de 2018].

Plumer, M. C. Los tribunales ambientales: se completa la reforma a la institucionalidad ambiental. [En línea]. En Anuario de Derecho Público. 2013, n. 1, 297-315. Disponible en: http://derecho.udp.cl/wp-content/uploads/2016/08/013_Plumer.pdf [Consultado el 18 de diciembre de 2018].

Primer Tribunal Ambiental. Ministros del 1TA concluyen visita inspectiva a faena de Pascua Lama. [En línea]. Primer Tribunal Ambiental. Febrero de 2018. Disponible en: https://www.1ta.cl/minitros-del-1ta-concluyen-visita-inspectiva-a-faena-de-pascualama/ [Consultado el 9 de marzo de 2018].

PrING, G. y PRING, K. Environmental Courts and Tribunal Study and Global Environmental Outcomes LLC. A Guide for Policy Makers. [En línea]. Nairobi, Kenya: UN Environment, Law Division. Septiembre de 2016. Disponible en: https://wedocs.unep.org/ bitstream/handle/20.500.11822/10001/environmental-courts-tribunals.pdf?sequence $=1$ [Consultado el 9 de enero de 2019].

Puschel, L. y Urrutia, O. Principios del derecho internacional ambiental. [En línea]. Pontificia Universidad Católica de Valparaíso. Disponible en: http://ocw.pucv.cl/ cursos-1/derecho-ambiental-internacional/materiales-de-clases-1/catedras/clase-3/ clase-3-principios-del-derecho-internacional-ambiental-apuntes [Consultado el $12 \mathrm{de}$ enero de 2019].

Riquelme, C. Los tribunales ambientales en Chile. ¿Un avance hacia la implementación del derecho de acceso a la justicia ambiental? [En línea]. Revista Catalana de Dret Ambiental. 2013, vol. 4, n. ${ }^{\circ}$ 1, 1-43. Disponible en: https://revistes.urv.cat/index.php/ rcda/article/view/1335 [Consultado el 18 de diciembre de 2018].

Rojas, H. y García, M. E. Rol del Tribunal Ambiental Administrativo: protección y prevención en materia ambiental. [En línea]. Revista de Ciencias Económicas. 2008, vol. 26, n. ${ }^{\circ}$ 1, 91-113. Disponible en: https://revistas.ucr.ac.cr/index.php/economicas/article/ view/7158/6839 [Consultado el 7 de enero de 2019].

URRUTIA, O. Jurisprudencia nacional, nuevos tribunales ambientales y derecho internacional del medio ambiente. [En línea]. En Revista de Derecho de la Pontificia Universidad Católica de Valparaíso. 2013, n. 40, 475-507. Disponible en: https://scielo.conicyt.cl/ pdf/rdpucv/n40/a15.pdf [Consultado el 18 de diciembre de 2018].

\section{Normatividad chilena}

Ley 1552 de 1902, Código de Procedimiento Civil. [En línea]. Disponible en: https://www. leychile.cl/Navegar?idNorma=22740 [Consultado el 31 de diciembre de 2018].

Ley 19.039 de 1991, Ley de Propiedad Industrial. [En línea]. Disponible en: https://www. leychile.cl/Navegar?idNorma=30406 [Consultado el 31 de diciembre de 2018].

Ley 19.886 de 2003, Ley de Bases sobre Contratos Administrativos de Suministro y Prestación de Servicios. [En línea]. Disponible en: https://www.leychile.cl/Navegar?idNorma=213004 [Consultado el 31 de diciembre de 2018]. 
Ley 20.322 de 2009, Ley Orgánica de Tribunales Tributarios y Aduaneros. [En línea]. Disponible en: https://www.leychile.cl/Navegar?idNorma=286151 [Consultado el 31 de diciembre de 2018].

Ley 19.911 de 2003, Crea el Tribunal de la Libre Competencia. [En línea]. Disponible en: https://www.leychile.cl/Navegar?idNorma=217122 [Consultado el 31 de diciembre de 2018].

Ley 18.961 de 1990, Ley Orgánica de Carabineros de Chile. [En línea]. Disponible en: https:/ www.leychile.cl/Navegar?idNorma=30329 [Consultado el 31 de diciembre de 2018].

Decreto Ley 2.460 de 1979, Dicta Ley Orgánica de la Policía de Investigaciones de Chile. [En línea]. Disponible en: https://www.leychile.cl/Navegar?idNorma=6926 [Consultado el 31 de diciembre de 2018].

Decreto Ley 2.859 de 1979, Fija Ley Orgánica de Gendarmería de Chile. [En línea]. Disponible en: https://www.leychile.cl/Navegar?idNorma=7015 [Consultado el $31 \mathrm{de}$ diciembre de 2018].

Ley 16.618 de 1967, Fija el texto definitivo de la Ley de Menores. [En línea]. Disponible en: https://www.leychile.cl/Navegar?idNorma=28581 [Consultado el 31 de diciembre de 2018].

Ley 15.231 de 1963, Fija el texto definitivo y refundido de la Ley de Organización y Atribuciones de los Juzgados de Policía Local. [En línea]. Disponible en: https://www. leychile.cl/Navegar?idNorma=28104 [Consultado el 31 de diciembre de 2018]

Ley 18.510 de 1986, Crea Juzgados de Letras del Trabajo, establece procedimientos en materias laborales, modifica el Código Orgánico de Tribunales, la Ley n. ${ }^{\circ} 14.972$ y los decretos leyes n. ${ }^{\circ} 2.758$ y 3.648 , de 1979 y 1981, respectivamente. [En línea]. Disponible en: https://www.leychile.cl/Navegar?idNorma=29910 [Consultado el 31 de diciembre de 2018].

Decreto con Fuerza de Ley n. ${ }^{\circ}$, de 2002, del Ministerio el Trabajo y Previsión Social, Fija el texto refundido, coordinado y sistematizado del Código del Trabajo. [En línea]. Disponible en: https://www.leychile.cl/Navegar?idNorma=207436 [Consultado el 31 de diciembre de 2018].

Decreto n. 1120, de 1983, del Ministerio de Justicia, Reglamento de la Ley 18.216. [En línea]. Disponible en: https://www.leychile.cl/Navegar?idNorma=16899 [Consultado el 31 de diciembre de 2018].

\section{Normatividad extranjera}

Asamblea Legislativa de la República de El Salvador. Decretos n. ${ }^{\circ} 684$, n. ${ }^{\circ}$ 8, n. ${ }^{\circ} 172$, n. 215 , n. ${ }^{\circ} 535$ y n..$^{\circ}$ 574. [En línea]. Disponibles en: http://www.csj.gob.sv/Comunicaciones/2017/03_MARZO/IMAGES/MA/Decreto\%20Legislativo\%20684\%20-Creaci\%C3\%B3n\%20 Juzgados\%20Ambientales.pdf [Consultado el 13 de marzo de 2018]. 


\section{Jurisprudencia}

National Green Tribunal of India. Caso Mehta v. Union of India. Sentencia del 23 de agosto de 2016. [En línea]. Disponible en: https://drive.google.com/file/ d/0BzXilfcxe7yuYVpFstzyntmyN1E/view [Consultado el 2 de marzo de 2018].

Segundo Tribunal Ambiental de Chile. Causa Rol D-06-2013, Estado de Chile / Servicios Generales Larenas Ltda. [En línea]. Disponible en: http://consultas.tribunalambiental. cl/ambiental_portal/Web/Portal/LEX _ POR_ExpedienteCausa.aspx?q=qwwvEXYDPdG eq/+h7eqnhxvezUCLuSU2Or+rO7HhUGjFJ6cmGNkZzf5/DkpTG2mBoJcpr7P04DLR1fsyZS8IgCP4xUFooyNiW3V9nyh9KeQ= [Consultado el 22 de febrero de 2018].

Segundo Tribunal Ambiental de Chile. Causa Rol D-15-2015, "Ilustre Municipalidad de Maipú / Minera Española Chile Limitada”. [En línea]. Disponible en: http://consultas. tribunalambiental.cl/ambiental_portal/Web/Portal/LEX _ POR_ExpedienteCausa.asp $\mathrm{x}$ ?q=qw wvEXYDPdGeq/+h7eqnh60vGLMqP+vfWI31+ENKYv3SdDaROavuPEBEYDMzAQ 41Hv1RxDH6gXGr+AfjAF5R+FAqgOgHmTh0/8Yj84Yj3w4= [Consultado el 22 de febrero de 2018].

Supreme Court of India. Caso Mehta v. Union of India (Kanpur Tanneries), sentencia de 1988. [En línea]. Disponible en: http://www.globalhealthrights.org/asia/m-c-mehta-vunion-of-india-kanpur-tanneries/ [Consultado el 2 de marzo de 2018].

Tercer Tribunal Ambiental de Chile. Causa Rol D-25-2017, "Ilustre Municipalidad de Pitrufquén con Empresa de Ferrocarriles del Estado y otra". [En línea]. Disponible en: https://causas.3ta.cl/causes/168/expedient/3807/?attachmentId=6023 [Consultado el 21 de febrero de 2018].

Tercer Tribunal Ambiental de Chile. Causa Rol D-34-2018, "Comité de Defensa Patrimonial de los Ángeles (codepala) con I. Municipalidad de Los Ángeles". [En línea]. Disponible en: https://causas.3ta.cl/causes/215/expedient/4197/?attachmentId=6577 [Consultado el 21 de febrero de 2018].

Tercer Tribunal Ambiental de Chile. Causa Rol R-6-2014, "Empresa Nacional de Electricidad S.A. con Superintendencia del Medio Ambiente". [En línea]. Disponible en: https://causas.3ta.cl/causes/84/expedient/1413/?attachmentId=1832 [Consultado el 31 de diciembre de 2018].

Tribunal Constitucional de Chile. Causa Rol 541-06, del 13 de julio de 2006, Requerimiento de inaplicabilidad presentado por la Corte de Apelaciones de Santiago respecto del inciso primero del artículo 42 del DFL n. . 164, de 1991 (Ley de Concesiones), en relación a la causa caratulada "Autopista Central S.A. con Servicio de Mecánica Mantención Track S.A.", Rol n. ${ }^{\circ}$ 2.097-2006, seguida ante la Corte de Apelaciones de Santiago. [En línea]. Disponible en: http://www.tribunalconstitucional.cl/wp/ver.php?id=129 [Consultado el 9 de enero de 2019].

\section{Documentos}

Congreso Nacional de Chile. "Historia de la Ley n. ${ }^{\circ} 20.600$, Crea los Tribunales Ambientales". [En línea]. Biblioteca del Congreso Nacional de Chile. Disponible en: https://www. bcn.cl/obtienearchivo?id=recursoslegales/10221.3/37272/1/HL20600.pdf [Consultado el 27 de diciembre de 2018]. 
Congreso Nacional de Chile. Protocolo de acuerdo proyecto de ley que crea el Ministerio y la Superintendencia del Medio Ambiente. [En línea]. Boletín 5947-12. 26 de octubre de 2009. Disponible en: http://www.uchile.cl/documentos/protocolo-de-acuerdo-proyectode-ley-que-crea-el-ministerio-y-la-superintendencia-del-medio-ambiente_57732_3.pdf [Consultado el 27 de diciembre de 2018].

Primer Tribunal Ambiental de Chile. Causa Rol R-1-2017, “Andes Iron SpA. con Servicio de Evaluación Ambiental". [En línea]. Disponible en: https://causas.1ta.cl/causes/4/ expedient/297/?attachmentId=571 [Consultado el 22 de febrero de 2018]. 